\title{
APLIKASI AUGMENTED REALITY UNTUK KARTU ANGGOTA SEBAGAI PORTOFOLIO DIGITAL
}

\author{
Rahmad Kurniawan $^{1}$,Nur Rubiati ${ }^{2}$, Rionaldo ${ }^{3}$ \\ ${ }^{1,2,3}$ Sekolah Tinggi Manajemen Informatika dan Komputer (STMIK) Dumai \\ JL. Utama Karya Bukit Batrem Kec. Dumai Timur Kode pos 28811 \\ e-mail :nurrubiati0412@gmail.com ${ }^{1}, \underline{\text { rahmad0412@gmail.com }}{ }^{2}, \underline{\text { rionaldosinaga@gmail.com }}^{3}$
}

\begin{abstract}
ABSTRAK
Kartu anggota umumnya hanya menampilkan informasi secara umum, dimana detail informasi orang terbatas dan bersifat pribadi. Sebuah kartu anggota juga kurang menarik untuk sebuah perkenalan di perusahaan ataupun untuk kepentingan bisnis jika hanya menampilkan informasi bersifat umum saja. Disini penulis ingin membuat teknologi Augmented Reality, yaitu teknologi yang menggabungkan benda maya berupa objek yang dibentuk oleh komputer ke dalam sebuah lingkungan nyata tiga dimensi, lalu memproyeksikan benda benda tersebut ke dalam waktu nyata. Dengan memanfaatkan teknologi Augmented Reality ini, informasi seperti portofolio yang biasanya digunakan untuk memberikan informasi umum kepada pembaca sebenarnya, bisa diubah ke dalam bentuk informasi 3 dimensi yang ditampilkan secara virtual di kartu anggota, lalu objek virtual tersebut dapat dilihat dengan menggunakan perangkat smartphone. Aplikasi ini dibuat dengan menggunakan Unity yang merupakan suatu game development yang mampu digunakan membuat game dalam berbagai macam platform. Dengan kartunya yang nantinya dapat karyawan dapat mengetahui informasi sangat mudah.
\end{abstract}

Kata Kunci : Augmented Reality, Smartphone, Kartu anggota, Portofilio Digital

\section{ABSTRACT}

Membership cards generally only display information in general, where details are limited and personal information. A membership card is also less attractive for an introduction to a company or for business purposes if it only displays general information. Here the author wants to make Augmented Reality technology, which is a technology that combines virtual objects in the form of objects formed by computers into a real three-dimensional environment, then projects these objects into real time. By utilizing this Augmented Reality technology, information such as portfolios that are normally used to provide general information to actual readers, can be transformed into 3-dimensional information that is displayed virtually on a membership card, then the virtual object can be viewed using a smartphone device. This application was created using Unity which is a game development that can be used to make games on various platforms. With the card, employees can find out information very easily later

\section{Keywords: Augmented Reality, Smartphone, Membership Card, Portofilio Digital}

\section{PENDAHULUAN}

Kartu nama biasanya berisi nama, nomornomor yang dapat dihubungi, alamat perusahaan. Kartu nama juga dapat berisikan informasi lainnya sesuai dengan identitas yang ingin diberikan oleh pemilik kartu nama. Saat menerima kartu nama dari orang lain, beberapa penerima akan menyimpan kartu nama tersebut di dalam saku, dompet, atau tempat khusus kartu nama.Lalu kemudian kartu nama tersebut akan kembali dicari saat akan menghubungi seseorang yang bersangkutan. (Putri, Puspitaningrum, \& Setiawan, 2018, h.1). Desain kartu anggota harus sesuai dengan karakter usaha / person yang diwakili, dalam hal ini perorangan maupun perusahaan sehingga bisa meningkatkan image profesionalnya. Untuk itu, kartu anggota harus menunjukkan siapa pemiliknya dan memberikan informasi mengenai segala hal yang bisa dilakukan oleh pemilik dan juga layanan yang bisa diberikan di masa mendatang. 
IN F O R M A I I A

Jurnal Informatika, Manajemen dan Komputer, Vol. 12 No. 1, Mei 2020

eISSN : 2580-3042

pISSN : 1979-0694

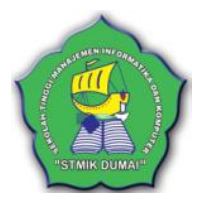

Kartu anggota umumnya hanya menampilkan informasi secara umum, dimana detail informasi orang terbatas dan bersifat pribadi. Sebuah kartu anggota juga kurang menarik untuk sebuah perkenalan di perusahaan ataupun untuk kepentingan bisnis jika hanya menampilkan informasi bersifat umum saja. Ada informasi yang dibutuhkan oleh perusahaan tapi tidak tertulis pada kartu anggota dan ini menjadi masalah pada sebagian perusahaan.

Disini penulis memanfaatkan teknologi Augmented Reality, yaitu teknologi yang menggabungkan benda maya berupa objek yang dibentuk oleh komputer ke dalam sebuah lingkungan nyata tiga dimensi, lalu memproyeksikan benda benda tersebut ke dalam waktu nyata. Dengan memanfaatkan teknologi Augmented Reality ini, informasi seperti portofolio yang biasanya digunakan untuk memberikan informasi umum kepada pembaca sebenarnya, bisa diubah ke dalam bentuk informasi 3 dimensi yang ditampilkan secara virtual di kartu anggota, lalu objek virtual tersebut dapat dilihat dengan menggunakan perangkat smartphone.

Untuk itu perlu dibuat sebuah aplikasi yang dapat memberikan informasi portofolio yang lebih mengarah kepada CV (Curriculum Vitae), agar informasi yang ditampilkan lebih detail, menarik dan interaktif pada kartu anggota.

\section{a. Smartphone}

Menurut (Mandias, 2017) Smartphone merupakan sebuah device yang memungkinkan untuk melakukan komunikasi juga didalamnya terdapat fungsi PDA (Personal Digital Assistant) dan berkemampuan seperti layaknya komputer. Dalam pengembangan awal, kita hanya mengenal adanya handphone dan PDA. Handphone pada umumnya digunakan untuk melakukan komunikasi seperti menelpon, sedangkan PDA digunakan sebagai asisten pribadi dan organizer.

\section{b. Aplikasi}

Secara istilah pengertian aplikasi adalah suatu program yang siap untuk digunakan yang dibuat untuk melaksanankan suatu fungsi bagi pengguna jasa aplikasi serta penggunaan aplikasi lain yang dapat digunakan oleh suatu sasaran yang akan dituju (Ilmiah, Komputa, Volume, Issn, \& Juansyah, 2015, h.2). Aplikasi sering juga disebut sebagai perangkat lunak, merupakan program komputer yang isi instruksinya dapat diubah dengan mudah (Syani, 2018, h.88).

\section{c. Data}

Data adalah sesuatu yang belum mempunyai arti bagi penerimanya dan masih memerlukan adanya suatu pengolahan. Data bisa berwujud suatu keadaan, gambar, suara, huruf, angka, matematika, bahasa ataupun simbolsimbol lainnya yang bisa kita gunakan sebagai bahan untuk melihat lingkungan, obyek, kejadian ataupun suatu konsep. (Iswandy, Sekolah, Manajemen, Komputer, \& Balantai, 2015).

\section{d. Augmented Reality}

Augmented reality merupakan teknologi interkasi yang menggabungkan antara dunia nyata (real world) dan dunia maya (virtual world). Teknologi Augmented reality merupakan salah satu trobosan yang digunakan pada akhirakhir ini di dibidang interaksi. Penggunaan teknologi ini akan sangat membantu dalam menyampaikan suatu informasi kepada pengguna. (Martono, 2015). Augmented Reality dapat digunakan dalam berbagai kegiatan, seperti presentasi, memperkirakan suatu obyek, peralatan perangsang kinerja, mensimulasikan suatu kinerja alat, dan lain-lain. Beberapa contoh tersebut merupakan gambaran pemanfaatan Augmented Reality secara umum (Mustaqim, Pd, \& Kurniawan, 2017)

\section{e. Unity}

Unity merupakan suatu game development ecosystem yang mampu digunakan untuk membuat game dalam berbagai macam platform baik console, desktop, dan mobile. Bahasa pemrograman utama Unity adalah C\# dengan IDE Mono Develop. Dalam unity disediakan berbagai pilihan bahasa pemrograman untuk mengembangkan game, antara lain JavaScript, C Sharp (C\#), dan BooScript. (Ericksoon, Kuswardayan, \& Suciati, 2016, h.621). Dengan memanfaatkan teknologi multimedia, presentasi akan lebih interaktif dan menarik. (Mashadi, $2010: 155)$

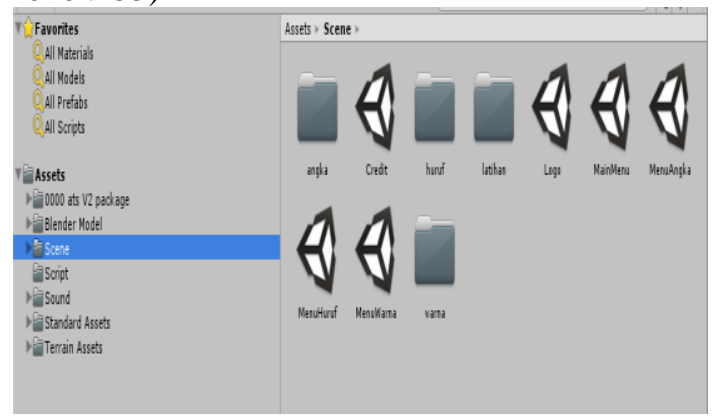

Gambar 1. Asset di dalam unity (Eridani, Arfan, \& Game, 2016) 
IN F ORMA TIK

Jurnal Informatika, Manajemen dan Komputer, Vol. 12 No. 1, Mei 2020

eISSN : 2580-3042

pISSN : 1979-0694

\section{f. Tiga Dimensi (3D)}

Menurut Irham Fa'idh Faiztyan Objek (Aplikasi \& Unityd, 2015) 3D atau objek tiga dimensi adalah sebuah objek / atau ruang yang memiliki panjang, lebar dan tinggi yang memiliki panjang, lebar dan tinggi yang memiliki bentuk 3D tidak hanya digunakan dalam matematika dan fisika saja melainkan dibidang grafis, seni, animasi ,komputer dan lain lain.

\section{g. Informasi}

Informasi adalah hasil pengolahan data dalam bentuk yang lebih berguna dan lebih berarti, yang menggambarkan kejadian (event) yang nyata ( fact), dan dapat digunakan untuk pengambilan keputusan. (Tinggi, Informatika, Dumai, Utama, \& Ii, 2017).

\section{h. Bahasa Pemograman C\#}

Menurut (Purnama \& Putra, 2018) Bahasa

C\# tidak didistribusikan sebagai produk mandiri, C\# bagian dari Microsoft .NET Framework platform (diucapkan "Microsoft Dot Net Framework") .NET Framework umumnya terdiri dari lingkungan untuk pengembangan dan pelaksanaan program, ditulis dalam bahasa $\mathrm{C}$ \# atau yang lainnya Bahasa, kompatibel dengan .NET (seperti VB.NET, Managed $\mathrm{C}++, \mathrm{J} \#$ atau F \#). Yang terdiri dari :

1. Bahasa pemrograman NET. (C \#, VB.NET dan lainnya);

2. Lingkungan untuk eksekusi kode yang dikelola, yang mana menjalankan program $C$ \# secara terkendali;

3. Satu set perpustakaan standar, seperti ADO.NET, yang memungkinkan akses ke Database (seperti $M S$ SQL Server atau $M y S Q L)$ dan $W C F$ yang terhubung aplikasi melalui kerangka komunikasi str dan protokol seperti soket HTTP, REST, JSON, SOAP dan TCP.

\section{i. Vuforia SDK}

Vuforia merupakan software untuk augmented reality, yang menggunakan sumber yang konsisten mengenai computer vision yang fokus pada image recognition. Vuforia mempunyai banyak fitur-fitur dan kemampuan, yang dapat membantu pengembang untuk mewujudkan pemikiran mereka tanpa adanya batas secara teknikal (Ilmiah et al., 2014, h.3).

Dengan support untuk iOS, Android, dan Unity3D, platform Vuforia mendukung para pengembang untuk membuat aplikasi yang dapat digunakan di hampir seluruh jenis smartphone dan tablet. Pengembang juga diberikan kebebasan untuk mendesain dan membuat aplikasi yang mempunyai kemampuan antara lain:

1. Teknologi computer vision tingkat tinggi yang mengijinkan developer untuk membuat efek khusus pada mobile device.

2. Dapat mengenali lebih dari satu gambar.

3. Tracking dan Detection tingkat lanjut.

4. Solusi pengaturan database gambar yang fleksibel.

\section{METODOLOGI PENELITIAN}

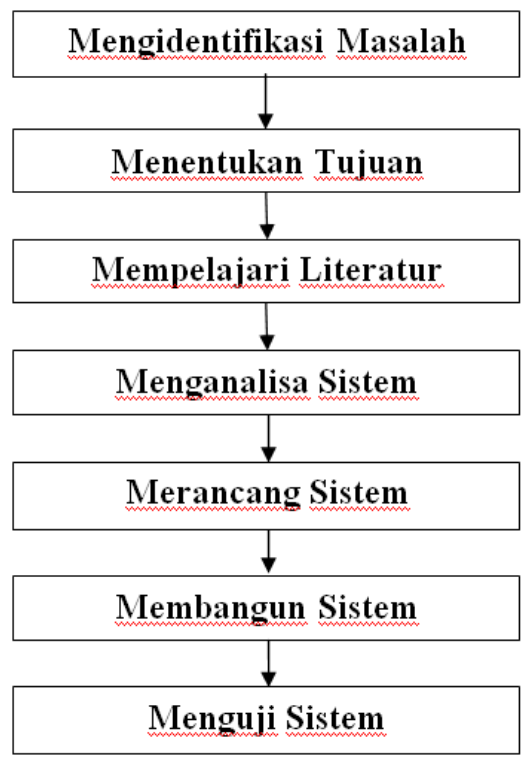

Gambar 2. Kerangka Kerja

1. Mengindentifikasi Masalah

Tahapan pertama yang dilakukan dalam penelitian adalah mengetahui persoalan ata masalah-masalah yang ingin membuat penelitian tentang Augmented Reality pada kartu anggota.

2. Menentukan Tujuan Peneliatan

Adapun tujuan dari penelitian ini adalah untuk memberikan penyajian yang lebih terbaik dan interaktif secara real-time agar pengguna dapat mengenal pemilik kartu anggota tersebut.

3. Mempelajari Literatur

Pengumpulan data dengan cara mempelajari sumber kepustakaan diantaranya hasil penelitian, indeks, review, jurnal, paper, buku refrensi, dan bacaan bacaan yang ada kaitannya dengan judul penelitian.

4. Menganalisa Sistem 
IN F O R M A I I A

Jurnal Informatika, Manajemen dan Komputer, Vol. 12 No. 1, Mei 2020

elSSN : 2580-3042

pISSN : 1979-0694

akan dipakai dalam melakukan proses pembuatan aplikasi Augmented Reality pada smartphone Android serta menganalisis cara kerja sistem aplikasi yang akan dibuat untuk membuat proses perancangan.

5. Merancang Sistem

Melakukan perancangan aplikasi yang akan dibuat, mengacu pada hasil analisis terhadap studi literature yang dilakukan dan mengikuti aturan standar perancangan aplikasi berbasis pemrogaman berorientasi objek.

6. Membangun Sistem

Pada Tahap ini dilakukan pembangunan sistem berdasarkan perancangan sistem yang telah dilakukan sebelumnya dengan menggunakan unity, vuforia SDK dan Android yang menggunakan teknologi Augmented Reality dengan marker.

7. Menguji Sistem

Pada tahap ini, perancangan aplikasi direalisasikan sebagai serangkaian program atau unit yang telah memenuhi spesifikasinya serta untuk mengetahui adanya bug dan error yang mungkin akan terjadi dengan tujuan apakah aplikasinya berjalan sesuai dengan yang diinginkan.

Metode penelitian yang digunakan untuk membangun aplikasi augmented reality untuk kartu anggota sebagai portofolio digital dilakukan dengan cara:

1. Metode Lapangan (Field Research)

Yaitu pengamatan yang dilakukan di lapangan untuk memperoleh data dan informasi yang diperlukan mengenai teknis kegiatan presentasi yang telah dilakukan selama ini untuk menemukan objek-objek permasalahan. Adapun teknik yang dilakukan adalah :

a. Interview atau wawancara yaitu mencari dan mengumpulkan data atau informasi yang akan digunakan, mencari jawaban atas masalah yang mungkin timbul pada saat perancangan aplikasi.

b. Observasi atau pengamatan langsung ke objek penelitian guna memperoleh data atau gambaran serta keterangan terhadap aplikasi yang sedang berjalan.

2. Penelitian Labor (Laboratory Research)

Yaitu merancang sistem dari data dan informasi yang telah diperoleh dari hasil pengamatan dengan menggunakan komputer untuk pengetikan teks, membuat pengolahan data dan melakukan serangkaian uji coba untuk menyelesaikan pembuatan program aplikasi.

3. Penelitian Pustaka (Library Research)

Dalam hal ini akan dilakukan pengumpulan serta analisis bahan-bahan yang berasal dari buku-buku, jurnal, tesis, youtube, proposal maupun teori-teori serta referensi terhadap datadata yang dibutuhkan sebagai pendukung dalam pembuatan skripsi ini.

\section{HASIL DAN PEMBAHASAN}

\section{Analisis Sistem}

Analisis sistem dapat didefinisikan sebagai penguraian dari suatu sistem informasi yang utuh kedalam bagian-bagian komponennya dengan maksud untuk mengidentifikasi dan mengevaluasi permasalahan-permasalahan, kesempatan- kesempatan, hambatan-hambatan yang terjadi dan kebutuhan-kebutuhan yang diharapkan sehingga dapat diusulkan perbaikanperbaikannya. Sistem yang untuk saling mengenal antar sesama karyawan masih menggunakan kartu anggota pada umumnya, yang mana hanya menampilkan informasi secara umum, dimana detail informasi orang terbatas dan bersifat pribadi Sebuah kartu anggota juga kurang menarik untuk sebuah perkenalan di perusahaan ataupun untuk kepentingan bisnis jika hanya menampilkan informasi bersifat umum saja. Ada informasi yang dibutuhkan oleh perusahaan tapi tidak tertulis pada kartu anggota

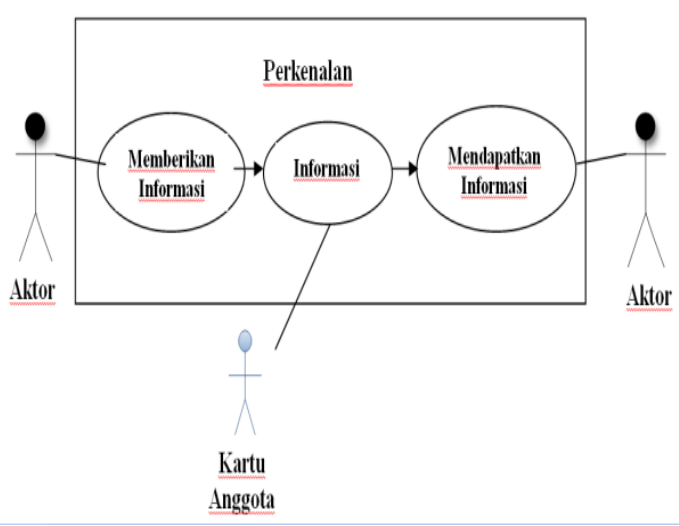

Gambar 3. Use Case Analisis Sistem

\section{Analisis Kebutuhan Sistem}

Aplikasi Augmented Reality Untuk Kartu Anggota Sebagai Portofolio Digital ini merupakan aplikasi berbasis Augmented reality. Aplikasi ini dapat dijadikan alternatif untuk memberikan informasi tentang portofolio pribadi yang lebih menarik dan interaktif agar pengguna dapat lebih mengenal pemilik kartu anggota tersebut. Karena aplikasi ini adalah produk 
IN F O R M A I I A

Jurnal Informatika, Manajemen dan Komputer, Vol. 12 No. 1, Mei 2020

eISSN : 2580-3042

pISSN : 1979-0694

berbasis AR yang menggunakan marker sebagai pola pelacakan atau tracking marker, maka dibutuhkan komputer dan perangkat lunak sebagai pengolah citra dan marker.

Aplikasi yang dibuat merupakan program untuk mendeteksi sebuah kartu anggota yang sudah menjadi marker pada aplikasi tersebut, lalu sekaligus menampilkan objek 3 dimensi melalui kamera smartphone yang berisi tentang informasi berupa portofolio anggota karyawan yang lebih lengkap. Dan pengguna juga dapat berinteraksi langsung dengan objek virtual muncul diatas kartu anggota tersebut. Adapun Use Case pada aplikasi berhubungan dengan aplikasi dan penggunaan Augmented Reality pada sistem ini. Dimana diagram Use Case ini lebih bagaimana pengguna dapat menjalankan fungsi-fungsi yang terdapat pada aplikasi.

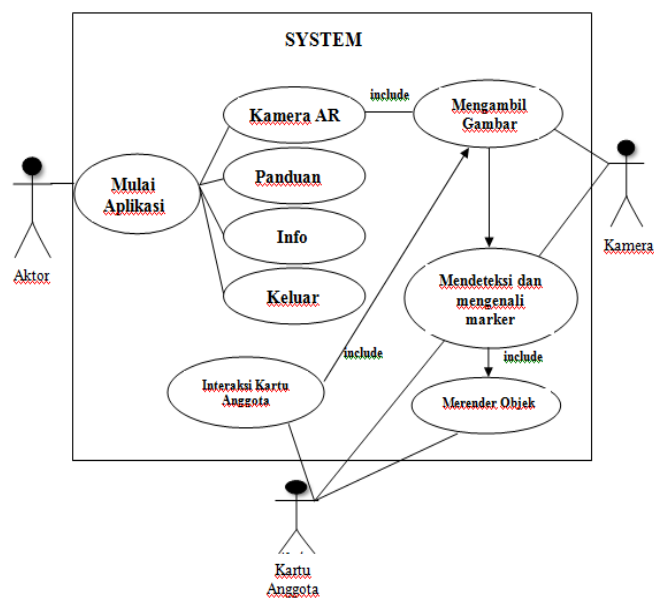

Gambar 4 Use Case Kebutuhan Sistem

a. Kebutuhan Input Proses dan Output

Dari Analisis Use Case yang sudah dijabarkan maka dapat ditentukan semua kebutuhan sistem seperti input, proses dan output dapat dilihat dari tabel berikut :

Tabel 1. Kebutuhan Kebutuhan

\begin{tabular}{|c|c|c|}
\hline $\begin{array}{l}\text { Kebutuhan } \\
\text { Input }\end{array}$ & $\begin{array}{c}\text { Kebutuhan } \\
\text { Proses }\end{array}$ & $\begin{array}{c}\text { Kebutuhan } \\
\text { Output }\end{array}$ \\
\hline $\begin{array}{l}\text { 1. Kartu anggota } \\
\text { 2. Informasi } \\
\text { karyawan } \\
\text { 3. Smartphone } \\
\text { android }\end{array}$ & $\begin{array}{l}\text { Smartphone } \\
\text { Android }\end{array}$ & $\begin{array}{l}\text { Kartu } \\
\text { anggota } \\
\text { yang sudah } \\
\text { terdaftar dan } \\
\text { ada } \\
\text { informasi } \\
\text { didalamnya. }\end{array}$ \\
\hline
\end{tabular}

\section{Pemodelan Proses}

Pemodelan proses adalah teknik mengelola dan mendokumentasikan struktur dan aliran data melalui proses system dan logika, kebijakan dan prosedur yang akan di implementasikan oleh proses sistem. Adapun salah satu pemodelan terstruktur yang digunakan untuk membuat aplikasi ini, diantaranya adalah Context Diagram dan Data Flow Diagram.

\section{a Context Diagram}

Berikut ini merupakan langkah dan cara kerja dari Prototype Otomatisasi dan Pemantauan 
IN F ORMA T I K A

Jurnal Informatika, Manajemen dan Komputer, Vol. 12 No. 1, Mei 2020

eISSN : 2580-3042

pISSN : 1979-0694

Sistem Pengisian Air Secara Realtime, sebagai berikut.

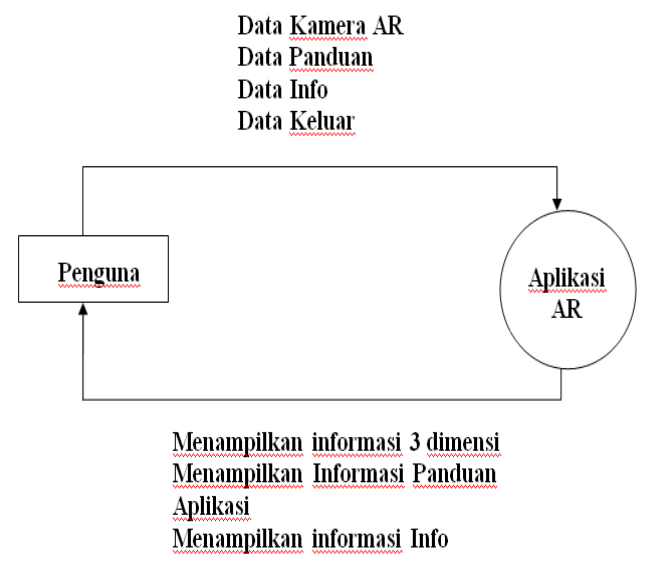

Gambar 5. Context Diagram Pemodelan Proses

\section{Pemodelan Output}

Pemodelan output adalah pemodelan input yang telah diproses menjadi bentuk yang dapat digunakan atau informasi yang disampaikan kepada pengguna yang menggunakan sistemnya. Hasil informasi yang ditampilkan diciptakan dengan menggunakan cara manual, yaitu dengan membuat gambar yang berisi informasi informasi penting, lalu dikonversikan dalam bentuk 3 dimensi dengan menggunakan aplikasi SketchUp. Hasil informasi yang didapatkan setelah kamera AR pada aplikasi ini menampilkan seperti gambar berikut

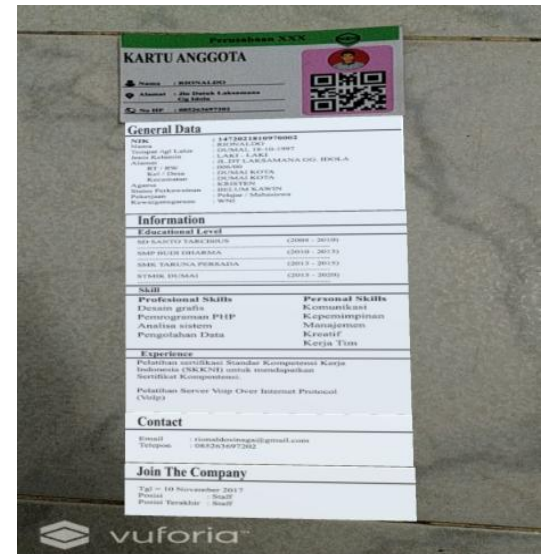

Gambar 7. Pemodelan Output

a Pemodelan Output Informasi

Pada pemodelan output untuk membuat informasi yang akan ditampilkan disisi bawah kartu nama tersebut, disini penulis membuat menggunakan aplikasi Adobe Photoshop CS6

untuk membuat objek dasarnya sebelum dikonversikan kedalam 3 dimensi.

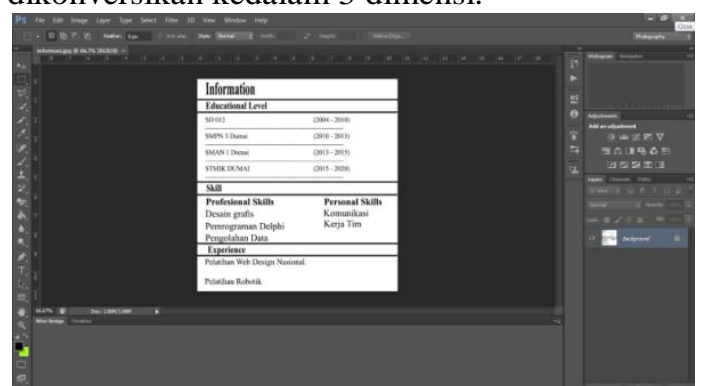

Gambar 8. Pemodelan Output Informasi

\section{b Pemodelan Output Informasi Kedalam 3 Dimensi}

Disini penulis menggunakan aplikasi SketchUp untuk mengkonversikan gambar yang berisi informasi ke dalam bentuk 3 dimensi.

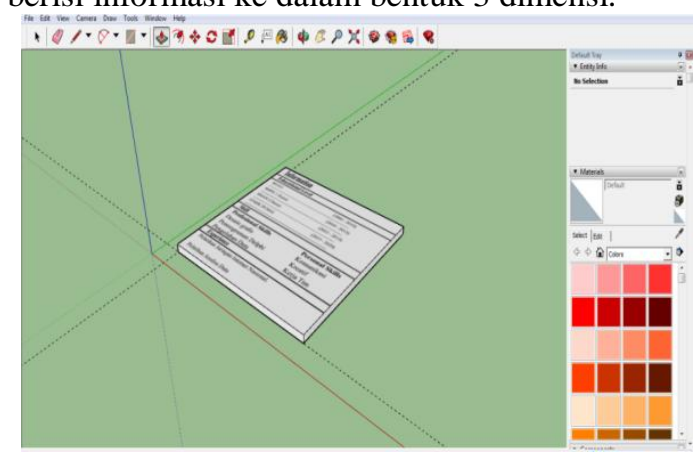

Gambar 9. Pemodelan Output ke dalam 3D

\section{Pemodelan Input}

Pemodelan input adalah salah satu cara untuk mendapatkan sebuah hasil yang sebelumnya sudah diproses terlebih dahulu. Untuk mendapatkan informasi karyawan berbentuk 3 dimensi maka dibutukan sebuah marker. Disini penulis menggunakan sebuah kartu anggota sebagai markernya.

\section{a Pemodelan Input Kartu Anggota}

Pada pemodelan input kartu anggota atau marker yang digunakan sebagai indentitas dari informasi karyawan yang ingin ditampilkan, disini penulis merancang model kartu anggota nya dengan menggunakan Photoshop CS 6 dan menggunakan aplikasi QR-Code Studio untuk merancang QR kode yang ada di dalam kartu anggota tersebut. 
IN F ORMA T I K A

Jurnal Informatika, Manajemen dan Komputer, Vol. 12 No. 1, Mei 2020

eISSN : 2580-3042

pISSN : 1979-0694

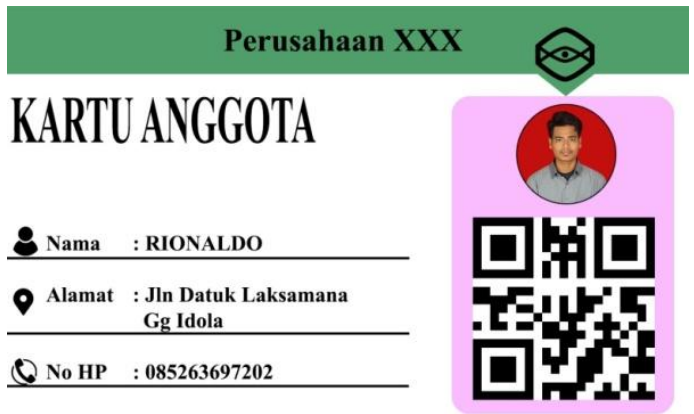

Gambar 10. Desain Kartu Anggota

b Pemodelan QR Code / Kode Batang

Pada perancangan QR Code didalam kartu anggota yang digunakan untuk membuat perbedaan antar salah satu kartu anggota, maka disini penulis menggunakan aplikasi QR Studio dan menggunakan NIP atau angka unik sebagai kode batangnya contoh : 2154034

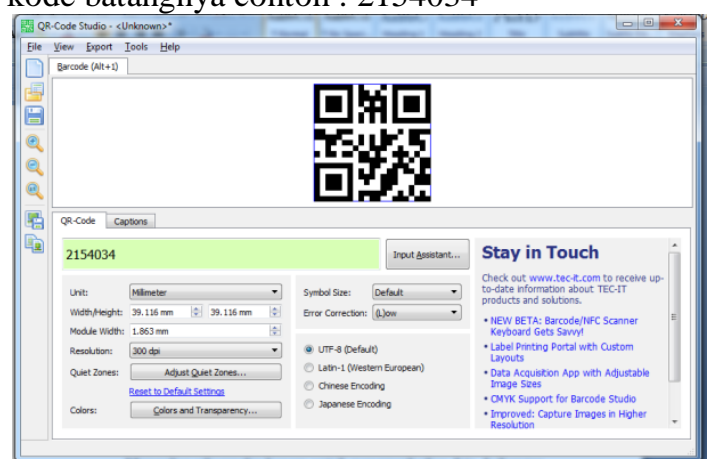

Gambar 11. Pembuatan Kode Batang

c Pemodelan QR Code / Kode Batang

Pada perancangan kartu anggota disini penulis menggunakan aplikasi Adobe Photoshop CS6 dengan menggunakan ukuran lebar 1417 dan tinggi 866 piksel dan resolusi yang digunakan adalah 400 piksel dengan mode warna Grayscale 8 bit.

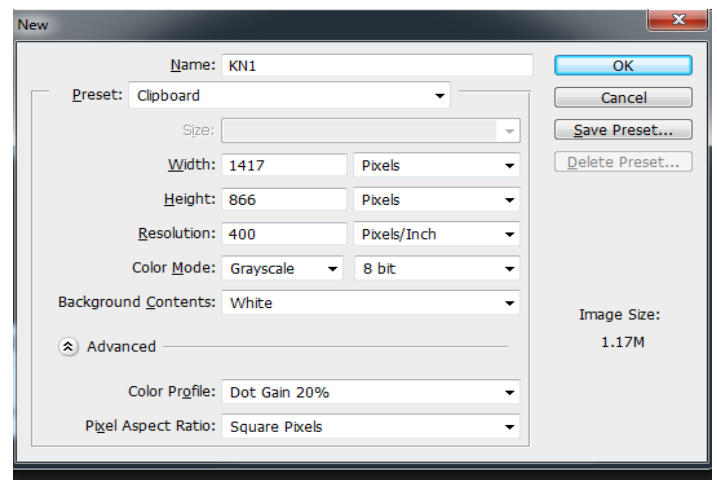

Gambar 12. Spesifikasi Ukuran Kartu Anggota di Photoshop CS6

\section{B. Pemodelan Logika dan Algoritma}

Flowchart adalah sebuah jenis diagram yang mewakili algoritma, alir kerja atau proses, yang menampilkan langkah-langkah dalam bentuk simbol-simbol grafis, dan urutannya dihubungkan dengan panah. Diagram ini mewakili ilustrasi atau penggambaran penyelesaian masalah. Pemodelan logika yang dipakai untuk membuat aplikasi ini adalah sebagai berikut

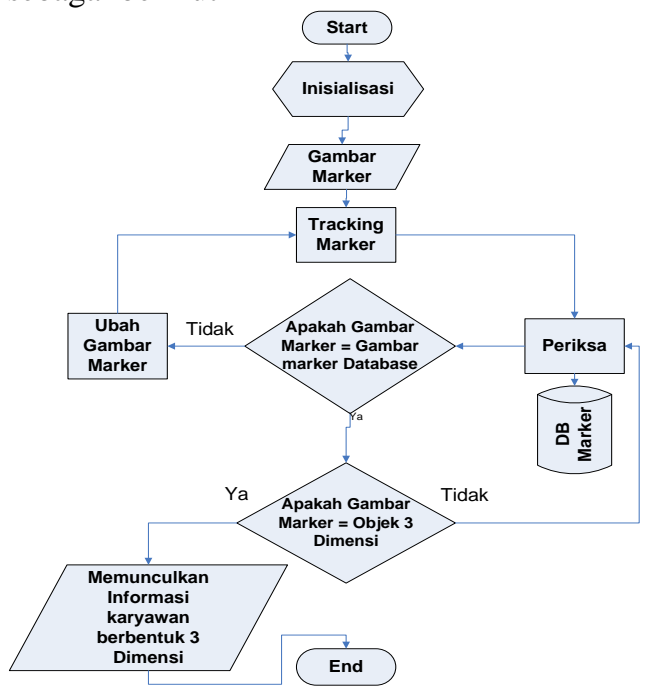

Gambar 13. Gambar Pemodelan Logika (Flowchart)

\section{KESIMPULAN}

Setelah selesai dilakukan maka dapat diambil beberapa kesimpulan sebagai berikut :

1. Dengan aplikasi hasil penelitian, ini seluruh karyawan di perusahaan sangat mudah untuk mengetahui informasi antar karyawan yang lebih lengkap.

2. Cara berkenalan dengan menerapkan tenkologi augmented reality ini, dapat memberikan pengalaman baru dalam dunia interaksi, karena berinteraksi langsung dengan objek virtual.

3. Dengan aplikasi ini pihak perusahaan dapat dipermudah dalam meminta informasi karyawan, karena sudah ada fitur untuk membagikan ke sosial media ataupun layanan surel online.

\section{REFERENSI}

Aplikasi, P., \& Unityd, M. (2015). Perancangan Dan Pembuatan Aplikasi Visualisasi 3d Interaktif Masjid Agung Jawa Tengah Menggunakan Unity3d, 3(2), 207-212. 
I N F O R M A T I K A

Jurnal Informatika, Manajemen dan Komputer, Vol. 12 No. 1, Mei 2020

eISSN : 2580-3042

pISSN : 1979-0694

Ericksoon, H. A., Kuswardayan, I., \& Suciati, N. (2016). Rancang Bangun Game Berhitung Spaceship Dengan Pengendali Suara Menggunakan Speech Recognition Plugin Pada Unity, 5(2).

Iswandy, E. (2015). Jurnal Tesknoif Issn : 2338 2724 Sistem Penunjang Keputusan Untuk Menentukan Penerimaan Mahasiswa Dan Pelajar Kurang Mampu Vol . 3 No . 2 Oktober 2015 Jurnal Teknoif Issn: 23382724, 3(2).

Juansyah, A. (2015). Pembangunan Aplikasi Child Tracker Berbasis Assisted - Global Positioning System ( A-Gps ) Dengan Platform Android Jurnal Ilmiah Komputer Dan Informatika ( Komputa ).

Mandias, G. F. (2017). Analisis Pengaruh Pemanfaatan Smartphone Terhadap Prestasi Akademik Mahasiswa Fakultas Ilmu Komputer Universitas Klabat, 3(1).

Martono, K. T. (2015). Augmented Reality Sebagai Metafora Baru Dalam Teknologi Interaksi Manusia Dan Komputer, 1(2), 60 64.

Purnama, R. Ad., \& Putra, A. T. L. (2018). Aplikasi Web Server Berbasis Bahasa C Sharp, 4(1), 21-29.

Putri, D. Z., Puspitaningrum, D., \& Setiawan, Y. (2018). Konversi Citra Kartu Nama Ke Teks Menggunakan Teknik Ocr Dan JaroWinkler Distance, 12(1), 1-6.

Saputra, Y. A. (2014). Implementasi Augmented Reality ( Ar ) Pada Fosil Purbakala Di Museum Geologi Bandung Teknik Informatika - Universitas Komputer Indonesia Jurnal Ilmiah Komputer Dan Informatika ( Komputa ).

Suherni, S., Rubiati, N., \& Khumaini, H. (2017). Aplikasi Pendaftaran Dan Penerimaan Siswa Baru Di Smk Negeri 1 Rupat Berbasis Web, 9(2), 15-24. 